\title{
Evidence on the Extent and Potential Sources of Long Memory in U.S. Treasury Security Returns and Yields
}

\begin{tabular}{|c|c|c|}
\hline Robert A. Connolly** & Z. Nuray Güner & Kenneth N. Hightower \\
\hline CB3490, McColl Building & Department of Business Administration & ative Research \\
\hline Kenan-Flagler Business School & Middle East Technical University & Global Investment \\
\hline UNC - Chapel Hill & İnönü Bulvari 06531 & Management Corp. \\
\hline Chapel Hill, NC & Ankara, Turkey & 450 Lexington Avenue, Suite 3700 \\
\hline 27599-3490 USA & & New York, NY 10017-3943 \\
\hline connollr@bschool.unc.edu & nguner@ba.metu.edu.tr & khightower@federatedinv.com \\
\hline
\end{tabular}

May 2005

** - Corresponding author. We gratefully acknowledge helpful comments on earlier work made by seminar participants at the University of Toronto, the University of North Carolina - Chapel Hill, the January 2000 Econometric Society meetings, and the June 2001 meetings of the Society for Computational Economics at Yale University. This work has been supported by the Turkish Academy of Sciences, in the framework of the Young Scientist Award Program (EA-TÜBA-GEBÝP/2001-1-1). Comments and suggestions from Kit Baum, Basma Bekdache, Patrick Conway, Kris Jacobs, Mark Jensen, Bill Parke, Michael Salemi, the editor, Paul Evans, and two anonymous referees led to a much-improved paper. We are grateful to Aaron Smith for sharing his GAUSS code, to Gautam Kaul and Jennifer Conrad for making the original data set available to us, and to Paisan Limratanamongkol for updating the data. 


\title{
Evidence on the Extent and Potential Sources of Long Memory in U.S. Treasury Security Returns and Yields
}

\begin{abstract}
Unlike equity returns, many fixed-income return measures appear to display long memory. We show that the extent of long memory in U.S. Treasury debt returns differs strongly for gross and excess holding period returns. Granger and others have argued that long memory may only reflect infrequent structural breaks. We explore the impact of structural instability on tests for long memory. We find only weak indications that structural instability lies behind the long memory in gross and excess returns. The evidence of long memory remains strong for yield and term premia series even after accounting for a series of potential underlying structural changes.
\end{abstract}




\section{Evidence on the Extent and Potential Sources of Long Memory in U.S. Treasury Security Returns and Yields}

\section{Introduction}

Long memory has a checkered history in financial market research. Many studies have shown that both exchange rate and stock market volatility display long memory. Bollerslev and Mikkelsen (1996), Liu (2000), and Andersen, Bollerslev, Diebold, and Labys (2001) have all studied volatility models that capture long memory properties. By contrast, Lo (1991) and Lobato and Savin (1998) both showed that equity returns display little evidence of long memory. Indeed, Granger (1999) concludes that there is no reason to expect to see long memory in asset returns.

This paper extends the existing research on long memory in two ways. First, we show that holding period returns and yields on short-term U.S. Treasury securities display strong evidence of long memory. This contrasts sharply with the results for returns on U.S. Treasury bonds where we find no evidence of long memory. Further, we find that while there is long memory in gross holding period returns, excess holding period returns display only short-term memory.

The recent literature emphasizes that there is an important alternative interpretation of long memory tests. As Lobato and Savin (1998) note, evidence of an I(d) process may actually be structural instability in disguise. In addition, recent theoretical research identifies circumstances under which different types of structural instability can mimic the properties of long memory. ${ }^{1}$ This seems quite pertinent to our work: Gray (1996) and Ang and Bekaert (2002a, 2002b) provide ample evidence of regime switching in short-maturity yields (a specific form of instability).

The second principal contribution of the paper, then, is an investigation of the role of structural instability in producing evidence of long memory in U.S. bond markets. Using two different approaches to controlling for potential structural instability, we find only weak indications that structural instability explains our long memory evidence.

1. See Granger and Hyung (2004), Diebold and Inoue (2002), and Parke (1999). 
As a robustness check on our findings, we estimate directly the fractional differencing parameter. Since structural instability also affects the fractional differencing parameter estimates by causing shifts in the mean of variables, we control for potential shifts in mean while estimating these parameters. Based on these estimates, we confirm the robustness of our principal findings.

In the next section, we briefly review long memory tests, elaborate on the connection between long memory tests and structural change, and use a simple return and yield decomposition to motivate the relevance of these ideas in debt market research. Section III describes our data and presents the basic results of our long memory tests. We analyze the structural stability issues in Section IV, and summarize the results of our study in the final section.

\section{Section II. Long Memory, Confounding Events and Robustness}

\section{A. Long Memory Tests}

The long memory literature uses a number of tests. We focus primarily on the Kwiatkowski, Phillips, Schmidt, and Shin (KPSS, 1992) test. The KPSS test for I(0) behavior is consistent against an I(d) alternative, and it can be useful in distinguishing long memory from short memory. The null hypothesis of their test is that a time series is $\mathrm{I}(0)$, but under the alternative hypothesis, the time series displays $\mathrm{I}(\mathrm{d})$ behavior (with $\mathrm{d} \leq 1$ ). Lee and Schmidt (1996) provide Monte Carlo evidence that the KPSS test has power comparable to Lo's (1991) robust R/S statistic.

Using the partial sum $\left(S_{t}\right)$ of demeaned residuals, the KPSS test statistic is given by ${ }^{2}$

$$
\eta_{\mu}=T^{-2} \sum_{t=1}^{T} S_{t}^{2} / s_{T}^{2}(\ell)
$$

where the denominator is the Newey-West autocorrelation-consistent variance estimator. ${ }^{3}$

2. There is another version of the KPSS test, $\eta_{\tau}$, which is constructed in the same way except that the residuals are derived from a regression that involves a time trend as well as an intercept term.

3. More recently, Giraitis, et. al. (2003) present a rescaled variance test (V/S) for long memory that substitutes variances in (1). Their simulation results suggest the V/S test has better statistical properties than both the R/S and KPSS tests under some circumstances. 


\section{B. Confounding Events: Structural Break or Long Memory?}

What is needed for long memory empirical studies is a long sample realization of the process (i.e., 200 years), particularly one that is not sampled so often that short-run dependencies dominate the sample properties of the data. ${ }^{4}$ The difficulty faced in this study is that the underlying structures of debt markets, instruments, and trading institutions and practices have not been stable over our sample period (1962 - 1996).

The relationship between long memory and structural change has been the focus of increasing research recently. Some researchers (Diebold and Inoue (2002) and Granger and Hyung (2004)) see long memory as an artifact of processes that exhibit structural change over time. Others (e.g., Parke (1999)) propose models where structural breaks with random duration give rise to time series properties that are associated with long memory (i.e., slowly decaying autocorrelations).

In empirical studies, whether a process is deemed to be long memory or a structural break may come down to what types of tests are performed on the data. Hightower and Parke (2001) clarify this point by showing that structural shift tests and the KPSS test for I(d) (versus I(0)) behavior are both functions of the same term: the ratio of the partial sums of the series to a consistent variance estimate for that series. Furthermore, they show that these tests have nearly identical power against many common alternatives including structural change, unit roots and long memory. One interpretation of their theoretical results is that "large" KPSS test statistics may actually be evidence of structural shifts.

Andrews' (1993) supremum test for a one-time structural change with an unknown break point is a convenient way to see this. Given a time series of residuals defined in the usual manner (i.e., $\varepsilon_{i}=x_{i}-\bar{x}$ ), and defining $S_{t}=\sum_{i=1}^{t} \varepsilon_{i}$ to be the cumulative sum of squares, the LM test for a one-time change in mean at a point $\pi \in(0,1)$ may be written as

4. Bollerslev, Cai, and Song (2000), among others, provide a clever alternative approach to identifying and estimating long-run properties of return distributions from intraday data. The relative strengths of these different approaches remain an interesting topic for further research. 


$$
\mathrm{LM}_{\mathrm{T}}(\pi) \cong \frac{\mathrm{T}^{-1}}{\pi(1-\pi)} \mathrm{S}_{[\mathrm{T} \pi]}^{2} / \mathrm{s}^{2}(\ell)
$$

where

$$
\mathrm{s}^{2}(\ell)=\mathrm{T}^{-1} \sum_{\mathrm{t}=1}^{\mathrm{T}} \hat{\varepsilon}_{\mathrm{t}}^{2}+2 \mathrm{~T}^{-1}+\sum_{\nu=1}^{\mathrm{T}} \chi(\nu / \ell(\mathrm{T}))+\sum_{\mathrm{t}=\nu+1}^{\mathrm{T}} \hat{\varepsilon}_{\mathrm{t}} \hat{\varepsilon}_{\mathrm{t}-\mathrm{s}}
$$

If $x(v / \ell(T))$ is taken to be the Bartlett kernel, $s^{2}(\ell)$ is identical to the denominator of the KPSS statistic. The Andrews supLM test is $\sup L M_{\pi \in \Pi}(\pi)$ where $\Pi$ is bounded away from 0 and 1 . The KPSS test for stationarity can be viewed as an average of the $L M_{T}(\pi)$ terms weighted by $\pi(1-\pi)$. In this context, the supLM test can also provide insight into candidate breakpoints that may be driving rejections of short memory, if indeed these rejections are driven by a structural shift in the sample. ${ }^{5}$

\section{B.1. Effect of a Structural Break in a Fundamental Variable}

The long memory literature reports evidence that inflation rates display long memory. ${ }^{6}$ Given the ambiguity noted earlier in the interpretation of these tests, it is difficult to conclude whether the inflation series have long memory or structural breaks. Our concern here is whether inflation long memory (or structural breaks) can generate long memory evidence in our bond return and yield series.

Using the Fisher relation, we split the holding period return at time $\mathrm{t}$ on a riskless debt security with maturity of $\mathrm{j}$ months $\left(R_{j t}^{N}\right)$ into three parts: an expected real return for that horizon $\left(E\left(R_{j t}^{R}\right)\right)$, an inflation premium for that horizon $\left(E\left(\pi_{t}\right)\right)$, and a contemporaneous random marketwide shock term $\left(v_{t}\right)$ with mean zero:

$$
R_{j t}^{N}=E\left(R_{j t}^{R}\right)+E\left(\pi_{t}\right)+v_{t}
$$

5. Bai and Perron (2003) develop this idea further, showing that multiple breakpoints may be estimated by using a sequential procedure. In Section IV, we use their procedure to assess whether instability in several potential macroeconomic state variables may explain long memory evidence.

6. See Geweke and Porter-Hudak (1983), Hassler and Wolters (1995), Baillie, Chung, and Tieslau (1996), Baum, Barkoulas and Caglayan (1999), and Baillie, Han and Kwon (2002) for evidence that inflation is a fractionallyintegrated series. See also Backus and Zin (1993) for an early study connecting the inflation process to long memory and the term structure of interest rates. 
Significant productivity shocks may affect the real return on capital, and a variety of factors can affect the stability of the expected inflation process, central bank policy being a leading candidate.

The excess return is a linear combination of two holding period returns for securities with $j$ and $\mathrm{k}$ months until maturity (and $\mathrm{k}=1$ in practice):

$$
\begin{aligned}
& R_{j t}^{N}-R_{1 t}^{N}=E\left(R_{j t}^{R}\right)+E\left(\pi_{t}\right)+v_{t}-E\left(R_{1 t}^{R}\right)-E\left(\pi_{t}\right)-v_{t} \\
& R_{j t}^{N}-R_{1 t}^{N}=E\left(R_{j t}^{R}\right)-E\left(R_{1 t}^{R}\right) .
\end{aligned}
$$

Here, we assume that the inflation premium is independent of security maturity and the shock term is dominated by a market-wide component common to both maturities. This simple algebraic manipulation leads to the conjecture that excess holding period returns will not display long memory if inflation is the source of the long memory in gross holding period returns.

In yields, by contrast, the expected inflation varies with maturity because the yield reflects the expected inflation over the life of the bond. We hypothesize that the nominal yield at time $t$ on a riskless debt security with $\mathrm{j}$ periods until maturity $\left(Y_{j t}^{N}\right)$ depends on four factors: the real yield for that maturity $\left(Y_{j t}^{R}\right)$, the expected inflation rate over the life of the bond $\left(E\left(\pi_{j t}\right)\right)$, a maturity-specific disturbance term that captures shocks idiosyncratic to a particular maturity segment of the market $\left(v_{j t}\right)$, and a market-wide shock term $\left(v_{t}\right)$. Algebraically, we decompose the nominal yield as

$$
Y_{j t}^{N}=Y_{j t}^{R}+E\left(\pi_{j t}\right)+v_{j t}+v_{t}
$$

The term premium is then given by

$$
\begin{aligned}
& T P_{j-1, t}=Y_{j t}^{N}-Y_{1 t}^{N}=Y_{j t}^{R}+E\left(\pi_{j t}\right)+v_{j t}+v_{t}-Y_{1 t}^{R}-E\left(\pi_{1 t}\right)-v_{1 t}-v_{t} \\
& T P_{j-1, t}=Y_{j t}^{R}-Y_{1 t}^{R}+E\left(\pi_{j t}\right)-E\left(\pi_{1 t}\right)+v_{j t}-v_{1 t} .
\end{aligned}
$$

From (9), it is clear that structural breaks in the expected inflation series or maturity-specific shocks, either one-time or in a continuing sequence as in Parke (1999), might produce evidence of long memory in the term premium series. Of course, by (7), it is also clear that structural breaks in expected inflation or maturity-specific shocks might produce long memory in the yield series, too. 
As a practical matter, we use the Bai-Perron (2003) procedure to identify the structural breaks in the inflation series. Then, we calculate the long memory test statistics again for each of the subsamples identified from applying the Bai-Perron procedure to the inflation series.

\section{B.2. Effect of a Structural Break in a Latent Variable}

Instead of pinpointing structural change in a fundamental variable as the cause of a structural break/long memory in the bond return and yield series, we can also assume that structural instability is precipitated by a latent variable. We further assume that we can identify the shifts in this latent variable by analyzing the return and yield series directly. Using the Hamilton's (1994) markov switching model, we can identify the structural breaks in our bond return and yield series. Then, the long memory tests are recalculated for the subsamples identified in this way.

\section{Robustness Check: Bias-adjusted d-parameter}

A common approach to diagnosing long memory is to estimate the fractional differencing parameter, $\mathrm{d}$, from an $\operatorname{ARFIMA}(0, \mathrm{~d}, 0)$ time-series model, $(1-L)^{d} \cdot y_{t}=\varepsilon_{t}$ where $d \in(-.5, .5)$ and $E\left(\varepsilon_{t}, \varepsilon_{t-j}\right)=0, \forall j>0$. Geweke and Porter-Hudak (1983) outline a simple strategy for estimating the value of $d$, and other researchers have presented alternative estimators. ${ }^{7}$

When a time series is generated by a mean plus noise $(\mathrm{MN})$ model with short memory, Smith (2005) shows that the GPH estimator has a substantial positive bias. The MN model class is fairly general, and it includes markov-switching and random level-shift models as special cases. Smith derives a modified GPH estimator that minimizes this bias, and suggests comparing the standard and bias-adjusted GPH estimates of $d$. When the standard estimate of $d$ is larger than the bias-adjusted estimate of $d$, this indicates that a mean shift may be masquerading as long memory. If the bias-adjusted GPH estimate is larger, any long memory is not likely due to structural shifts.

\section{Section III. Data and Preliminary Results}

\section{A. Return and Yield Data}

7. For a recent survey of these issues, see Banerjee and Urga (2005), particularly Section 3. 
In the subsequent empirical analysis, we analyze gross and excess holding period returns on U.S. Treasury securities in addition to Treasury yields and term premia, all observed on a weekly basis. The basic return data set contains weekly holding period returns on one-, three-, six-, and 12month Treasury Bills and three-, five-, and 10-year Treasury Bonds for the July 1962 through May 1996 period. $^{8}$ The yield data consist of weekly observations on three-, six-, and 12-month Treasury Bills and three-, five-, and 10-year Treasury bonds. We describe each in turn.

Weekly holding period returns were calculated by taking the log difference of this Wednesday's bid price and last Wednesday's ask price and adding in the percentage return associated with accrued interest. The bid and ask prices used to calculate the weekly return were for the same security, but the security used in the computations was altered so as to maintain a fairly constant maturity return series. In no case, though, were prices on different securities used to make return computations. Treasury bill and bond price data is from The Wall Street Journal. ${ }^{9}$

We computed six excess return measures as the weekly holding period return on a longer maturity Treasury security (10-year, five-year, three-year bonds, 12-month, six-month, three-month bills) less the weekly holding period return on one-month bills. This gives the extra return earned by holding a longer-maturity (vs. short-maturity) Treasury debt instrument.

The yield data is from the Federal Reserve Bank of St. Louis. We calculate the term premia studied here by subtracting the yield on three-month bills from the yield on 12-month (bill), threeyear, five-year, and 10-year bonds.

8. The original weekly return data was collected by Gautam Kaul and updated by Paisan Limratanamongkol.

9. One motivation for using individual security data is to avoid aggregation of multiple security returns where possible. Granger and Joyeux (1980) analyze aggregation as a source of long memory. 


\section{Section IV. Empirical Findings}

\section{A. Long Memory Test Results}

The results of the KPSS tests are reported in Panel A of Table $1 .^{10}$ For all nine return series except the weekly returns on five- and 10-year Treasury bonds, the null hypothesis of stationarity is strongly rejected in favor of an $\mathrm{I}(\mathrm{d})$ process. The evidence of persistence is even stronger in the yields and term-premia, where almost every time series rejects stationarity in every situation.

When applied to weekly excess holding period returns, the KPSS test statistics produce very little evidence of long-term dependence. This stands in sharp contrast to our just-noted findings about long memory in gross holding period returns. It is consistent with the hypothesis based on the decomposition in Section II.B.1. that inflation instability may be the source of long memory in gross holding period returns. It also confirms the approach of empirical asset pricing work that focuses on excess returns and ignores long memory altogether. ${ }^{11}$

\section{B. Confounding Events: Structural Break or Long Memory?}

\section{B.1. Macroeconomic Sources of Instability}

We consider the possibility that the long memory evidence just presented is an artifact of structural breaks in the data. Information on structural breaks in the data is only rarely directly observable. Therefore, to infer the timing of potential breaks, we look at structural instability in the inflation process as the underlying source of long memory evidence presented in Table $1 .{ }^{12}$ The advantage of this method is that we are not looking at the series with the apparent long memory to

10. Since the optimal number of autocovariances is not known ex ante, we compute $\hat{\eta}_{\mu}$ using a number of different lag lengths $(\ell)$.

11. We have also calculated the R/S and V/S statistics for comparison purposes. The results of R/S and V/S statistics are consistent with the evidence from the KPSS statistics. (Delete:We found the same pattern of results using the Giraitis, et. al. (2003) V/S statistic.) Therefore, to conserve space, these results are not reported in the paper, however, available from the authors upon request.

12. We also examined the role of structural breaks in the money supply process, again using the Bai-Perron method to identify the break points and applying the KPSS tests to the data in each subsample. We also apply the KPSS tests to data over subsamples constructed from the known changes in the Federal Reserve operating policies. Results of these analyses are very similar to the ones with inflation break points. To conserve space, these results are not reported in the paper, however, available from the authors upon request. 
find a structural break (and then using the structural break to argue that the long memory is an artifact of the structural break). This approach makes two assumptions: 1) inflation shocks are directly connected to structural breaks in the bond return and yield series, and 2) U.S. bond markets are relatively efficient so we take the estimated structural break points for this fundamental variable as break points for the bond return and yield series. Applying the KPSS tests to subsamples based on inflation breaks seems to have very little impact on the evidence for long memory (see Table 2).

\section{B.2. Modeling Shifts in a Latent Variable}

As an alternative to pinpointing structural change in a specific fundamental variable as the cause of a structural break/long memory in the bond return and yield series, we assume that structural instability is precipitated by a latent variable. However, we assume the shifts in this latent variable can be identified from the return and yield series directly. Building from Gray (1996) and Ang and Bekaert (2002a, 2002b), we apply Hamilton's (1994) markov switching model to time the structural breaks in our bond return and yield series. If this type of structural instability is behind the long memory evidence, we expect the evidence for long memory to weaken considerably (if not disappear) when we apply long memory tests to data from only one state.

For the return and yield series where strong evidence of long memory is documented (see Table 1), we find clear evidence of switching between two regimes over the full sample. In addition, the state persistence is considerable so that there are long stretches of time when the return or yield series is in a single state. This makes it relatively less difficult to identify the dates of breaks in these time series. For the series where we don't find robust evidence of long memory, state persistence parameters are uniformly smaller, and the state probabilities indicate much more frequent switching between states. Dating the breaks is correspondingly more difficult, of course. We note in passing that many of the subsamples chosen from the inflation break dates overlap regimes from the markov-switching model.

Perhaps the most interesting test centers on whether the long memory tests produce the same evidence on samples split using the regime shifts identified by the markov-switching model.

In Table 3, we report results from these tests for an illustrative subsample of our series. On the 
whole, the test statistics appear to confirm the basic evidence noted in Table 1. Many of the test statistics, however, are considerably smaller than before, suggesting that structural instability may have a limited role in explaining the long memory results reported in Table 1.

\section{Robustness Check: Bias-adjusted d-parameter Estimates}

We present GPH and biased-adjusted GPH estimates of the d parameter in Table 4. Recall that Smith's work implies that if infrequent mean shifts are the fundamental source of long memory, the modified GPH estimate of $d$ should be smaller than the regular GPH estimate.

For bill and five-year bond gross returns, comparison of the $\mathrm{d}$ estimates suggests that the long memory evidence reported in Table 1 is not a mean level shift model in disguise. For three and 10-year bond returns, estimates of $\mathrm{d}$ aren't significantly different from zero, indicating no long memory. Similarly, with one exception, the d estimates for excess returns indicate no long memory.

For bill and bond yields, the d estimates are about one for all maturities, and the biasadjusted point estimates of $\mathrm{d}$ are larger than the unadjusted estimates except for the shortest two maturities. In all cases, they aren't statistically different from one another. For the term premia, we find that the bias-adjusted $\mathrm{d}$ estimates are smaller than the unadjusted estimates, an indication that a mean shift may explain long memory. The differences in the $\mathrm{d}$ estimates are relatively small, and for bond term premia, the bias-adjusted estimates still indicate nonstationary long memory. These results are consistent with our findings from long memory tests.

\section{Section V. Summary and Further Discussion}

There is reasonably widespread agreement that financial asset volatility displays long memory, but the evidence is mixed at best for other financial time series. One contribution of this paper has been to show that Treasury security gross holding period returns, yields, and term premia all display long memory, but excess returns do not. We also find that long memory in returns decreases as the maturity of the debt instrument increases. 
The KPSS test for long memory shares an important connection with structural instability tests, and this renders the interpretation of large KPSS test statistics problematic. Accordingly, the other purpose of our study has been to explore potential explanations of the long memory evidence.

We explored several different approaches to accounting for structural instability. Using a Fisher-effect decomposition, the first method studies shifts in the inflation process as a source of long memory. Our second approach assumed that shifts in a latent variable were the source of structural instability, and used Hamilton's markov-switching model to pick out potential breaks in the individual return, yield and term premia series. The results from both methods provide little evidence in favor of structural instability-based explanation for our long memory results.

Taken together, the bias-adjusted estimates of the fractional differencing parameter do not indicate that long memory is more likely due to a mean level shift. There might be other forms of structural instability that generate the long memory evidence, but given the wide variety of alternatives considered here, this interpretation of the data seems to be quite unlikely.

We believe it may prove interesting to assess the impact of long memory on term structure, bond pricing, and fixed income derivative models. Specifically, it would be useful to know whether long memory is related to any pricing biases and whether there are circumstances in which the impact of ignoring long memory is the most (and the least) noticeable. More fundamentally, our results suggest several stylized facts that a term structure/bond pricing model might have to explain: long memory in short-term yields and returns that decreases with maturity, but no long memory in excess returns. 
Table 1

\section{Tests for Long Memory}

Panel A: KPSS Test Results

\begin{tabular}{ccccccccccc} 
& \multicolumn{4}{c}{ Autocovariance Lag Length } & \multicolumn{4}{c}{ Autocovariance Lag Length } \\
Returns & $\underline{\mathbf{0}}$ & $\underline{\mathbf{4}}$ & $\underline{\mathbf{8}}$ & $\underline{\mathbf{1 2}}$ & $\underline{\text { Yields }}$ & $\underline{\mathbf{0}}$ & $\underline{\mathbf{4}}$ & $\underline{\mathbf{8}}$ & $\underline{\mathbf{1 2}}$ \\
1-month & $22.30^{*}$ & $5.33^{*}$ & $3.07^{*}$ & $2.18^{*}$ & 3-month & $30.11^{*}$ & $6.08^{*}$ & $3.41^{*}$ & $2.39^{*}$ \\
3-month & $12.07^{*}$ & $4.42^{*}$ & $2.81^{*}$ & $2.10^{*}$ & 6-month & $30.95^{*}$ & $6.24^{*}$ & $3.50^{*}$ & $2.45^{*}$ \\
6-month & $5.11^{*}$ & $2.63^{*}$ & $1.93^{*}$ & $1.60^{*}$ & $\mathbf{1 2 - m o n t h}$ & $33.89^{*}$ & $6.83^{*}$ & $3.83^{*}$ & $2.68^{*}$ \\
12-month & $1.99^{*}$ & $1.24^{*}$ & $1.03^{*}$ & $0.951^{*}$ & 3-year & $45.85^{*}$ & $9.23^{*}$ & $5.16^{*}$ & $3.60^{*}$ \\
3-year & $0.601^{*}$ & 0.405 & 0.356 & 0.347 & 5-year & $52.85^{*}$ & $10.63^{*}$ & $5.94^{*}$ & $4.14^{*}$ \\
5-year & 0.415 & 0.310 & 0.272 & 0.260 & $\mathbf{1 0 - y e a r}$ & $63.02^{*}$ & $12.66^{*}$ & $7.07^{*}$ & $4.92^{*}$ \\
10-year & 0.174 & 0.141 & 0.129 & 0.128 & & & & & \\
Excess Returns & & & & & & & & & \\
3m-1m & $0.708^{* *}$ & $0.562^{* *}$ & $0.515^{* *}$ & $0.493^{* *}$ & $\mathbf{1 2 m - 3 m}$ & $1.807^{*}$ & 0.391 & 0.230 & 0.169 \\
6m-1m & 0.209 & 0.154 & 0.140 & 0.138 & 3y-3m & $27.98^{*}$ & $5.80^{*}$ & $3.33^{*}$ & $2.38^{*}$ \\
12m-1m & 0.231 & 0.164 & 0.150 & 0.150 & $\mathbf{5 y - 3 m}$ & $32.85^{*}$ & $6.75^{*}$ & $3.86^{*}$ & $2.74^{*}$ \\
3y-1m & 0.422 & 0.293 & 0.261 & 0.257 & $\mathbf{1 0 y - 3 m}$ & $39.21^{*}$ & $8.02^{*}$ & $4.56^{*}$ & $3.23^{*}$ \\
5y-1m & 0.243 & 0.186 & 0.165 & 0.159 & & & & &
\end{tabular}

Notes: The KPSS test statistics reported here are calculated using (1) in the text. The number of lags in the autocovariance adjustment affects the consistent covariance matrix estimate. We indicate KPSS test statistics that reject the null hypothesis at the one (five) per cent significance level by ${ }^{*}{ }^{* *}$ ). 
Table 2

\section{KPSS Tests from Samples Split Using Inflation Break Points}

Panel A: Returns and Yields

\begin{tabular}{|c|c|c|c|c|c|c|c|c|c|}
\hline \multirow[b]{3}{*}{$\underline{\text { Sample }}$} & \multirow[b]{3}{*}{ Maturity } & \multicolumn{4}{|c|}{ Returns } & \multicolumn{4}{|c|}{ Yields } \\
\hline & & \multicolumn{4}{|c|}{ Autocovariance Lag Length } & \multicolumn{4}{|c|}{ Autocovariance Lag Length } \\
\hline & & $\underline{0}$ & $\underline{4}$ & $\underline{8}$ & $\underline{12}$ & $\underline{0}$ & $\underline{4}$ & $\underline{8}$ & $\underline{12}$ \\
\hline \multirow[t]{3}{*}{$1^{\text {st }}$} & 3-month & $13.13^{*}$ & $4.05^{*}$ & $2.41^{*}$ & $1.72^{*}$ & $21.67^{*}$ & $4.39^{*}$ & $2.47^{*}$ & $1.74^{*}$ \\
\hline & 12-month & $2.59^{*}$ & $1.27^{*}$ & $0.962^{*}$ & $0.790^{*}$ & $20.43^{*}$ & $4.14^{*}$ & $2.34^{*}$ & $1.65^{*}$ \\
\hline & 5-year & 0.243 & 0.149 & 0.122 & 0.107 & $20.63^{*}$ & $4.19^{*}$ & $2.36^{*}$ & $1.66^{*}$ \\
\hline \multirow[t]{3}{*}{$2^{\text {nd }}$} & 3-month & $2.31^{*}$ & $0.971^{*}$ & $0.640^{* *}$ & $0.493^{* *}$ & $7.67^{*}$ & $1.57^{*}$ & $0.89^{*}$ & $0.634^{* *}$ \\
\hline & 12-month & 0.305 & 0.210 & 0.182 & 0.166 & $6.28^{*}$ & $1.29^{*}$ & $0.74^{*}$ & 0.533 \\
\hline & 5-year & 0.407 & 0.277 & 0.257 & 0.251 & $5.30^{*}$ & $1.10^{*}$ & $0.63^{*}$ & 0.453 \\
\hline \multirow[t]{3}{*}{$3^{\text {rd }}$} & 3-month & $7.60^{*}$ & $3.38^{*}$ & $2.35^{*}$ & $1.873^{*}$ & $29.95^{*}$ & $6.11^{*}$ & $3.47^{*}$ & $2.45^{*}$ \\
\hline & 12-month & $0.585^{* *}$ & 0.356 & 0.325 & 0.333 & $32.22^{*}$ & $6.56^{*}$ & $3.72^{*}$ & $2.63^{*}$ \\
\hline & 5-year & 0.047 & 0.034 & 0.032 & 0.033 & $36.12^{*}$ & $7.35^{*}$ & $4.15^{*}$ & $2.92^{*}$ \\
\hline \multirow[t]{3}{*}{$4^{\text {th }}$} & 3-month & $20.40^{*}$ & $7.14^{*}$ & $4.38^{*}$ & $3.24^{*}$ & $42.77^{*}$ & $8.70^{*}$ & $4.89^{*}$ & $3.42^{*}$ \\
\hline & 12-month & $4.27^{*}$ & $3.03^{*}$ & $2.24^{*}$ & $1.84^{*}$ & $44.99^{*}$ & $9.14^{*}$ & $5.14^{*}$ & $3.61^{*}$ \\
\hline & 5-year & $1.80^{*}$ & $1.43^{*}$ & $1.16^{*}$ & $1.02^{*}$ & $50.24^{*}$ & $10.21^{*}$ & $5.76^{*}$ & $4.04^{*}$ \\
\hline
\end{tabular}

Panel B: Excess Returns and Term Premia

\begin{tabular}{|c|c|c|c|c|c|c|c|c|c|c|}
\hline \multirow[b]{3}{*}{$\underline{\text { Sample }}$} & \multicolumn{5}{|c|}{ Excess Returns } & \multicolumn{5}{|c|}{ Term Premia } \\
\hline & \multicolumn{5}{|c|}{ Autocovariance Lag Length } & \multirow[b]{2}{*}{ Maturity } & \multicolumn{4}{|c|}{ Autocovariance Lag Length } \\
\hline & Maturity & $\underline{0}$ & $\underline{4}$ & $\underline{8}$ & $\underline{12}$ & & $\underline{0}$ & $\underline{4}$ & $\underline{8}$ & $\underline{12}$ \\
\hline \multirow[t]{3}{*}{$1^{\text {st }}$} & $3 m-1 m$ & $2.05^{*}$ & $1.42^{*}$ & $1.10^{*}$ & $0.900^{*}$ & $12 \mathrm{~m}-3 \mathrm{~m}$ & $0.74^{*}$ & 0.184 & 0.123 & 0.098 \\
\hline & $12 \mathrm{~m}-1 \mathrm{~m}$ & $0.708^{* *}$ & 0.398 & 0.330 & 0.290 & $3 y-3 m$ & $7.32^{*}$ & $1.70^{*}$ & $1.09^{*}$ & $0.840^{*}$ \\
\hline & $5 y-1 m$ & 0.295 & 0.182 & 0.150 & 0.132 & $10 y-3 m$ & $18.34^{*}$ & $3.82^{*}$ & $2.21^{*}$ & $1.59^{*}$ \\
\hline \multirow[t]{3}{*}{$2^{\text {nd }}$} & $3 m-1 m$ & 0.266 & 0.232 & 0.208 & 0.203 & $12 \mathrm{~m}-3 \mathrm{~m}$ & $5.97^{*}$ & $1.34^{*}$ & $0.789^{*}$ & $0.577^{*}$ \\
\hline & $12 m-1 m$ & 0.111 & 0.084 & 0.078 & 0.075 & $3 y-3 m$ & $17.01^{*}$ & $3.58^{*}$ & $2.05^{*}$ & $1.45^{*}$ \\
\hline & $5 y-1 m$ & $0.470^{* *}$ & 0.321 & 0.299 & 0.292 & $10 y-3 m$ & $17.98^{*}$ & $3.68^{*}$ & $2.09^{*}$ & $1.47^{*}$ \\
\hline \multirow[t]{3}{*}{$3^{\text {rd }}$} & $3 m-1 m$ & 0.268 & 0.229 & 0.239 & 0.252 & $12 m-3 m$ & $10.53^{*}$ & $2.30^{*}$ & $1.36^{*}$ & $0.993^{*}$ \\
\hline & $12 \mathrm{~m}-1 \mathrm{~m}$ & 0.083 & 0.055 & 0.053 & 0.057 & $3 y-3 m$ & $3.93^{*}$ & $0.834^{*}$ & $0.489^{* *}$ & 0.355 \\
\hline & $5 y-1 m$ & 0.106 & 0.078 & 0.073 & 0.075 & $10 y-3 m$ & $5.89^{*}$ & $1.23^{*}$ & $0.715^{*}$ & $0.517^{* *}$ \\
\hline \multirow[t]{3}{*}{$4^{\text {th }}$} & $3 m-1 m$ & $2.099^{*}$ & $1.43^{*}$ & $1.05^{*}$ & $0.889^{*}$ & $12 m-3 m$ & $3.44^{*}$ & $0.733^{* *}$ & 0.436 & 0.325 \\
\hline & $12 \mathrm{~m}-1 \mathrm{~m}$ & $0.970^{*}$ & $0.824^{*}$ & $0.664^{* *}$ & $0.584^{* *}$ & $3 y-3 m$ & $14.70^{*}$ & $3.04^{*}$ & $1.75^{*}$ & $1.27^{*}$ \\
\hline & $5 y-1 m$ & $1.15^{*}$ & $0.943^{*}$ & $0.779^{*}$ & $0.697^{* *}$ & $10 y-3 m$ & $6.43^{*}$ & $1.31^{*}$ & $0.746^{*}$ & $0.529^{* *}$ \\
\hline
\end{tabular}

Notes: The KPSS test statistics reported here are calculated using (1) in the text. The number of lags in the autocovariance adjustment affects the nature of the consistent covariance matrix estimate. KPSS test statistics that indicate a rejection of the null hypothesis at the one (five) per cent significance level are indicated by $\left.{ }^{*}{ }^{* *}\right)$. The specific dates of the sample breaks are as follows: 1 : $7 / 4 / 62-5 / 3 / 67,2: 5 / 10 / 67$ 1/3/72, 3: 1/10/72 - 6/16/82, and 4: 6/23/82 - 5/29/96. 
Table 3

KPSS Tests from Samples Split Using Markov-Switching Model

\begin{tabular}{|c|c|c|c|c|c|c|c|c|c|}
\hline \multicolumn{5}{|c|}{ Bill and Bond Returns } & \multicolumn{5}{|c|}{ Bill and Bond Yields } \\
\hline \multirow{2}{*}{$\begin{array}{l}\text { 3-month Bills } \\
\text { Sample (Obs.) }\end{array}$} & \multicolumn{4}{|c|}{ Autocovariance Lag Length } & \multirow{2}{*}{$\begin{array}{l}\text { 3-month Bills } \\
\text { Sample (Obs.) }\end{array}$} & \multicolumn{4}{|c|}{ Autocovariance Lag Length } \\
\hline & $\underline{0}$ & $\underline{4}$ & $\underline{8}$ & $\underline{12}$ & & $\underline{0}$ & $\underline{4}$ & $\underline{8}$ & $\underline{12}$ \\
\hline $1(847)$ & $9.88^{*}$ & $4.18^{*}$ & $2.82^{*}$ & $2.12^{*}$ & $1(852)$ & $33.25^{*}$ & $6.77^{*}$ & $3.83^{*}$ & $2.70^{*}$ \\
\hline $2(351)$ & $0.702^{* *}$ & 0.391 & 0.303 & 0.271 & $2(410)$ & $16.65^{*}$ & $3.44^{*}$ & $1.99^{*}$ & $1.44^{*}$ \\
\hline \multirow[t]{3}{*}{$3(571)$} & $11.27^{*}$ & $4.31^{*}$ & $2.57^{*}$ & $1.84^{*}$ & $3(115)$ & $7.61^{*}$ & $1.72^{*}$ & $1.04^{*}$ & $0.777^{*}$ \\
\hline & & & & & $4(133)$ & $10.55^{*}$ & $2.20^{*}$ & $1.26^{*}$ & $0.925^{*}$ \\
\hline & & & & & $5(259)$ & $10.89^{*}$ & $2.21^{*}$ & $1.24^{*}$ & $0.875^{*}$ \\
\hline \multicolumn{5}{|l|}{ 10-year Bonds } & \multicolumn{5}{|l|}{ 10-year Bonds } \\
\hline $1(847)$ & 0.216 & 0.144 & 0.157 & 0.156 & $1(855)$ & $74.47^{*}$ & $15.03^{*}$ & $8.42^{*}$ & $5.87^{*}$ \\
\hline \multirow[t]{4}{*}{$2(351)$} & 0.223 & 0.182 & 0.166 & 0.164 & $2(403)$ & $6.73^{*}$ & $1.39^{*}$ & $0.793^{*}$ & $0.566^{* *}$ \\
\hline & & & & & $3(63)$ & $5.24^{*}$ & $1.15^{*}$ & $0.704^{* *}$ & $0.540^{* *}$ \\
\hline & & & & & $4(184)$ & $5.58^{*}$ & $1.20^{*}$ & $0.721^{* *}$ & $0.546^{* *}$ \\
\hline & & & & & $5(365)$ & $5.34^{*}$ & $1.10^{*}$ & $0.629^{* *}$ & 0.453 \\
\hline \multicolumn{5}{|c|}{ 3-Yr. Excess Returns } & \multicolumn{5}{|c|}{ 3-Yr. Term Premium } \\
\hline $1(924)$ & 0.327 & 0.214 & 0.201 & 0.198 & $1(469)$ & $8.44^{*}$ & $1.85^{*}$ & $1.10^{*}$ & $0.807^{*}$ \\
\hline $2(267)$ & 0.125 & 0.090 & 0.080 & 0.077 & $2(98)$ & $3.43^{*}$ & $0.748^{*}$ & 0.453 & 0.340 \\
\hline \multirow[t]{7}{*}{$3(678)$} & $0.535^{* *}$ & 0.398 & 0.324 & 0.294 & $3(112)$ & $7.71^{*}$ & $1.72^{*}$ & $1.05^{*}$ & $0.777^{*}$ \\
\hline & & & & & $4(187)$ & $11.10^{*}$ & $2.40^{*}$ & $1.41^{*}$ & $1.04^{*}$ \\
\hline & & & & & $5(159)$ & $3.60^{*}$ & $0.787^{*}$ & $0.485^{* *}$ & 0.376 \\
\hline & & & & & $6(371)$ & $7.42^{*}$ & $1.58^{*}$ & $0.940^{*}$ & $0.706^{* *}$ \\
\hline & & & & & 7 (117) & $8.07^{*}$ & $1.75^{*}$ & $1.06^{*}$ & $0.793^{*}$ \\
\hline & & & & & $8(220)$ & $2.49^{*}$ & $0.525^{* *}$ & 0.309 & 0.229 \\
\hline & & & & & $9(37)$ & $2.34^{*}$ & $0.539^{* *}$ & 0.353 & 0.300 \\
\hline
\end{tabular}

Notes: The KPSS test statistics reported here are calculated using (1) in the text. The number of lags in the autocovariance adjustment affects the nature of the consistent covariance matrix estimate. KPSS test statistics that indicate a rejection of the null hypothesis at the one (five) per cent significance level are indicated by $\left.{ }^{*}{ }^{* *}\right)$. Dates for the sample break points are as follows:

1) 3-month Gross Returns [1: 7/4/62 - 9/20/78, 2: 9/27/78 - 6/12/85, and 3: 6/19/85 - 5/29/96],

2) 10-year Gross Returns [1: 7/4/62 - 11/8/67 and 2: 11/15/67 - 5/29/96],

3) 3-year Excess Returns [1: 7/4/62 - 3/12/80, 2: 3/19/80 - 4/24/85, and 3: 5/1/85 - 5/29/96],

4) 3-month Yield [1: 7/4/62 - 10/25/78, 2: 11/1/78 - 9/10/86, 3: 9/17/86 - 11/30/88, 4: 12/7/91 - 6/19/91, and 5: 6/26/91 - 5/29/96],

5) 10-year Bond Yield [1: 7/4/62 - 11/15/78, 2: 11/22/78 - 8/13/86, 3: 8/19/86 - 11/4/87, 4: 11/11/87 - 5/8/91, and 5: 5/15/91 - 5/29/96],

6) 3-year Term Premium [1: 7/4/62 - 6/23/71, 2: 6/30/71 - 5/9/73, 3: 5/16/73 - 7/2/75, 4: 7/9/75 - 1/31/79, 5: 2/7/79 - 2/17/82, 6: 2/24/82 - 4/5/89, 7: 4/12/89 - 7/3/91, 8: 7/10/91 - 9/20/95, and 9: 9/27/95 - 5/29/96]. 
Table 4

\section{GPH and Modified GPH Estimates of Long Memory Parameter}

\begin{tabular}{|c|c|c|c|c|c|c|c|c|c|}
\hline \multirow[b]{2}{*}{$\underline{\text { Returns }}$} & \multicolumn{4}{|c|}{ Modified GPH $(\mathrm{k}=)$} & \multicolumn{5}{|c|}{ Modified GPH $(\mathrm{k}=)$} \\
\hline & $\underline{\text { GPH }}$ & $\underline{3}$ & $\underline{\mathbf{2}}$ & $\underline{4}$ & $\underline{\text { Yields }}$ & $\underline{\mathrm{GPH}}$ & $\underline{3}$ & $\underline{2}$ & $\underline{4}$ \\
\hline 1-month & $\begin{array}{l}0.675^{*} \\
(0.050)\end{array}$ & $\begin{array}{l}0.804^{*} \\
(0.077)\end{array}$ & $\begin{array}{l}0.824^{*} \\
(0.908)\end{array}$ & $\begin{array}{l}0.818^{*} \\
(0.068)\end{array}$ & 3-month & $\begin{array}{c}1.03^{*} \\
(0.050)\end{array}$ & $\begin{array}{l}1.02 * \\
(0.077)\end{array}$ & $\begin{array}{l}0.955^{*} \\
(0.908)\end{array}$ & $\begin{array}{c}1.05^{*} \\
(0.068)\end{array}$ \\
\hline 3-month & $\begin{array}{l}0.407^{*} \\
(0.050)\end{array}$ & $\begin{array}{l}0.634^{*} \\
(0.077)\end{array}$ & $\begin{array}{l}0.649^{*} \\
(0.908)\end{array}$ & $\begin{array}{l}0.603^{*} \\
(0.068)\end{array}$ & 6-month & $\begin{array}{l}0.930^{*} \\
(0.091)\end{array}$ & $\begin{array}{l}0.777^{*} \\
(0.148)\end{array}$ & $\begin{array}{l}0.908^{*} \\
(0.179)\end{array}$ & $\begin{array}{l}0.753^{*} \\
(0.130)\end{array}$ \\
\hline 6-month & $\begin{array}{l}0.305^{*} \\
(0.050)\end{array}$ & $\begin{array}{l}0.398^{*} \\
(0.077)\end{array}$ & $\begin{array}{l}0.423^{*} \\
(0.908)\end{array}$ & $\begin{array}{l}0.383^{*} \\
(0.068)\end{array}$ & 12-month & $\begin{array}{l}0.878^{*} \\
(0.101)\end{array}$ & $\begin{array}{l}0.917^{*} \\
(0.166)\end{array}$ & $\begin{array}{l}0.995^{*} \\
(0.202)\end{array}$ & $\begin{array}{l}0.853^{*} \\
(0.145)\end{array}$ \\
\hline 12-month & $\begin{array}{l}0.206^{*} \\
(0.050)\end{array}$ & $\begin{array}{l}0.194^{*} \\
(0.077)\end{array}$ & $\begin{array}{l}0.194^{*} \\
(0.908)\end{array}$ & $\begin{array}{l}0.219 * \\
(0.068)\end{array}$ & 3-year & $\begin{array}{l}0.896^{*} \\
(0.102)\end{array}$ & $\begin{array}{l}0.956^{*} \\
(0.168)\end{array}$ & $\begin{array}{c}1.04^{*} \\
(0.205)\end{array}$ & $\begin{array}{l}0.915^{*} \\
(0.147)\end{array}$ \\
\hline 3-year & $\begin{array}{l}-0.056 \\
(0.050)\end{array}$ & $\begin{array}{l}-0.227^{*} \\
(0.077)\end{array}$ & $\begin{array}{l}-0.335^{*} \\
(0.908)\end{array}$ & $\begin{array}{c}-0.134^{* *} \\
(0.068)\end{array}$ & 5-year & $\begin{array}{l}0.904^{*} \\
(0.107)\end{array}$ & $\begin{array}{l}1.04^{*} \\
(0.177)\end{array}$ & $\begin{array}{l}1.01^{*} \\
(0.216)\end{array}$ & $\begin{array}{l}0.994^{*} \\
(0.155)\end{array}$ \\
\hline 5-year & $\begin{array}{l}0.529^{*} \\
(0.050)\end{array}$ & $\begin{array}{l}0.757^{*} \\
(0.077)\end{array}$ & $\begin{array}{l}0.813^{*} \\
(0.908)\end{array}$ & $\begin{array}{l}0.722^{*} \\
(0.068)\end{array}$ & 10-year & $\begin{array}{l}0.937^{*} \\
(0.114)\end{array}$ & $\begin{array}{c}1.07^{*} \\
(0.192)\end{array}$ & $\begin{array}{c}1.08^{*} \\
(0.235)\end{array}$ & $\begin{array}{c}1.09^{*} \\
(0.167)\end{array}$ \\
\hline 10-year & $\begin{array}{l}-0.037 \\
(0.050)\end{array}$ & $\begin{array}{l}-0.213^{*} \\
(0.077)\end{array}$ & $\begin{array}{l}-0.320^{*} \\
(0.908)\end{array}$ & $\begin{array}{l}-0.101 \\
(0.068)\end{array}$ & & & & & \\
\hline
\end{tabular}

\section{Excess Returns}

$\begin{array}{ccccc}\text { 3m-1m } & 0.083 & 0.195^{*} & 0.173 & 0.151 \\ & (0.050) & (0.077) & (0.908) & (0.068) \\ \text { 6m-1m } & 0.075 & -0.169 & 0.008 & -0.59 \\ & (0.089) & (0.145) & (0.175) & (0.127) \\ \text { 12m-1m } & 0.014 & -0.029 & -0.088 & 0.002 \\ & (0.067) & (0.105) & (0.125) & (0.093) \\ \text { 3y-1m } & 0.038 & -0.036 & -0.026 & -0.006 \\ & (0.066) & (0.103) & (0.123) & (0.091) \\ \text { 5y-1m } & 0.105 & 0.105 & 0.057 & 0.08 \\ & (0.186) & (0.186) & (0.227) & (0.161) \\ \text { 10y-1m } & 0.038 & -0.036 & -0.026 & -0.006 \\ & (0.066) & (0.103) & (0.123) & (0.091)\end{array}$

\section{Term Premium}

$\begin{array}{ccccc}\text { 12m-3m } & 0.386^{*} & 0.053 & -0.074 & 0.16 \\ & (0.121) & (0.205) & (0.252) & (0.178) \\ 3 y-3 m & 0.804^{*} & 0.747^{*} & 0.663^{*} & 0.800^{*} \\ & (0.077) & (0.077) & (0.091) & (0.068) \\ 5 y-3 m & 0.841^{*} & 0.790^{*} & 0.724^{*} & 0.842^{*} \\ & (0.050) & (0.077) & (0.091) & (0.068) \\ \text { 10y-3m } & 0.872^{*} & 0.744^{*} & 0.753^{*} & 0.747^{*} \\ & (0.073) & (0.117) & (0.139) & (0.103)\end{array}$

Notes: Frequency-domain estimators of the differencing parameter, including Smith's modified GPH estimator require a bandwidth setting. In Smith, this is done by $(\mathrm{k} \cdot \mathrm{J}) / \mathrm{T}^{2}$, where $\mathrm{J}$ is the number of periodograms used to estimate $\mathrm{d}, \mathrm{T}$ is the sample size, and $\mathrm{k}$ is a scalar between 1 and 5 . (Following Geweke and Porter-Hudak's (1983) suggestion, it is common to implement the GPH estimator by setting $\mathrm{k}=1$ and $\mathrm{J}=\mathrm{T}^{(3 / 2)}$.) We focus primarily on estimates for $\mathrm{k}=3$, but we present estimates for other values of $\mathrm{k}$ following the recommendation in Smith. See Smith for further details, particularly Section 4.2. The estimates reported in this table use the full sample. Standard errors are in parentheses. A* indicates significance at the $1 \%$ level, and a* indicates significance at the $5 \%$ level. 


\section{REFERENCES}

Anderson, T. G., Bollerslev, T., Diebold, F. X., and Labys, P. (2001) "The Distribution of Exchange Rate Volatility," Journal of the American Statistical Association, 96, 42-55.

Andrews, D. W. (1993), “Tests for Parameter Instability and Structural Change with Unknown Change Point," Econometrica, 61, 821-856.

Andrews, D. W. and Ploberger, W. (1994), “Optimal Tests When a Nuisance Parameter is Present Only Under the Alternative," Econometrica, 62, 1383-1414.

Ang, A. and Bekaert, G. (2002a), "Short Rate Nonlinearities and Regime Switches," Journal of Economic Dynamics and Control, 26, $1243-1274$.

Ang, A. and Bekaert, G. (2002b), "Regime Switches in Interest Rates," Journal of Business and Economic Statistics, 20, 163-182

Backus, D. K., and Zin, S. E. (1993), "Long-Memory Inflation Uncertainty: Evidence from the Term Structure of Interest Rates," Journal of Money, Credit, and Banking, 25, 681-700.

Bai, J. and Perron, P. (2003), "Computation and Analysis of Multiple Structural Change Models," Journal of Applied Econometrics, 18, 1 - 22.

Baillie, R. T., Chung, C-F, and Tieslau, M. A. (1996), "Analyzing Inflation by the Fractionally Integrated ARFIMA-GARCH Model," Journal of Applied Econometrics, 11, 23-40.

Baillie, R. T., Han, Y-W., and Kwon T. (2002), "Further Long Memory Properties of Inflationary Shocks," Southern Economic Journal, 68, 496-510.

Banerjee, A. and Urga, G. (2005), "Modelling Structural Breaks, Long Memory and Stock Market Volatility: An Overview," Journal of Econometrics, forthcoming.

Baum, C. F., Barkoulas, J. T., and Caglayan, M. (1999), “Persistence in International Inflation Rates," Southern Economic Journal, 65, 900-913.

Bollerslev, T., Cai, J., and Song, F. (2000), "Intraday Periodicity, Long-Memory Volatility, and Macroeconomic Announcements Effects in the U.S. Treasury Bond Market," Journal of Empirical Finance, 7, 37-55.

Bollerslev, T., and Mikkelsen, H.-O. (1996), “Modeling and Pricing Long-Memory in Stock Market Volatility," Journal of Econometrics, 74, 3-30.

Diebold, F. X. and Inoue, A. (2002), "Long Memory and Regime Switching," Journal of Econometrics, 105, 131-159.

Geweke, J. and Porter-Hudak, S. (1983), "The Estimation and Application of Long Memory Time Series Models, Journal of Time Series Analysis, 4, 221-238. 
Giraitis, L., Kokoszka, P., Leipus, R., and Teyssiere, G. (2003), "Rescaled Variance and Related Tests for Long Memory in Volatility and Levels," Journal of Econometrics, 112, 265 - 294.

Granger, C. W. J., and Joyeux, R. (1980), "An Introduction to Long-Memory Time Series Models and Fractional Differencing," Journal of Time Series Analysis, 1, 15-29.

Granger, C. W. J. (1999), “Aspects of Research Strategies for Time Series Analysis," unpublished presentation to New Developments in Time Series Economics conference, New Haven, CT.

Granger, C. W. J., and Hyung, N. (2004), “Occasional Structural Breaks and Long Memory with an Application to the S\&P 500 Absolute Stock Returns," Journal of Empirical Finance, 11, 399-421.

Gray, S., (1996), "Modeling the Conditional Distribution of Interest Rates as a Regime-Switching Process," Journal of Financial Economics, 42, 27-62.

Hamilton, J., (1994), Time Series Analysis, (Princeton, N.J.: Princeton University Press).

Hassler, U. and Wolters, J. (1995), “Long Memory in Inflation Rates: International Evidence," Journal of Business and Economic Statistics, 13, 37-45.

Hightower, K. and Parke, W. (2001), "Stability," University of North Carolina-Chapel Hill Economics Department working paper.

Kwiatkowski, D., Phillips, P. C. B., Schmidt, P., and Shin, Y. (1992), "Testing the Null Hypothesis of Stationarity Against the Alternatives of a Unit Root: How Sure Are We That Economic Time Series Have a Unit Root?," Journal of Econometrics, 54, 159-178.

Lee, D. and Schmidt, P. (1996), "On the Power of the KPSS Test of Stationarity Against FractionallyIntegrated Alternatives," Journal of Econometrics, 73, 285-302.

Liu, M. (2000), “Modeling Long Memory in Stock Market Volatility," Journal of Econometrics, 99, 139171.

Lo, A. (1991), "Long-Term Memory in Stock Market Prices," Econometrica, 59, 1279-1313.

Lobato, I. N., and Savin, N. E. (1998), "Real and Spurious Long-Memory Properties of Stock-Market Data," Journal of Business and Economic Statistics, 16, 261-268.

Parke, W. R. (1999), “What is Fractional Integration?," Review of Economics and Statistics, 81, 632-638.

Smith, A. (2005), "Level Shifts and the Illusion of Long Memory in Economic Time Series," Journal of Business and Economics Statistics, forthcoming. 